Chapman University

Chapman University Digital Commons

Film Studies (MA) Theses

Dissertations and Theses

Spring 5-19-2019

\title{
Bending Family Friendly into Fear: Nostalgia, Minstrelsy and Horror in Bendy and the Ink Machine
}

Isabelle Williams

Chapman University, willi340@mail.chapman.edu

Follow this and additional works at: https://digitalcommons.chapman.edu/film_studies_theses

Part of the Film and Media Studies Commons

\section{Recommended Citation}

Williams, Isabelle. "Bending Family Friendly into Fear: Nostalgia, Minstrelsy and Horror in Bendy and the Ink Machine." Master's thesis, Chapman University, 2019. https://doi.org/10.36837/chapman.000073

This Thesis is brought to you for free and open access by the Dissertations and Theses at Chapman University Digital Commons. It has been accepted for inclusion in Film Studies (MA) Theses by an authorized administrator of Chapman University Digital Commons. For more information, please contact laughtin@chapman.edu. 
Bending Family Friendly into Fear:

Nostalgia, Minstrelsy, and Horror in Bendy and the Ink Machine

A Thesis by

Isabelle Catherine Williams

Chapman University

Orange, CA

Dodge College

Submitted in partial fulfillment of the requirements for the degree of

Masters of Arts in Film Studies

May 2019

Committee in charge

Dr. Kelli Fuery (Chair)

Dean Patrick Fuery

Dr. Stephanie Takaragawa 
The thesis of Isabelle Catherine Williams is approved

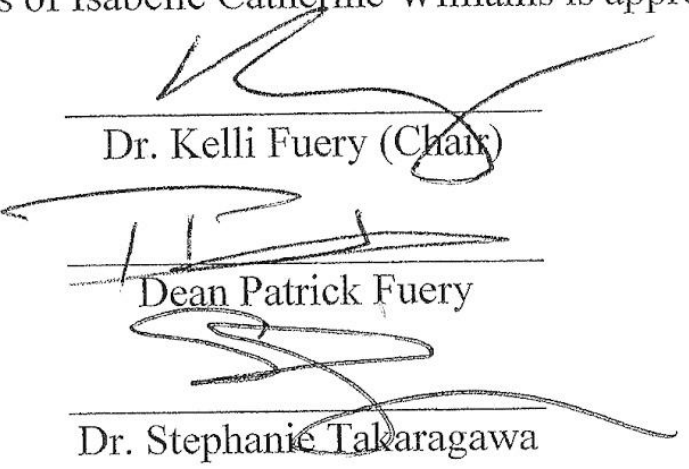

April 2019 
Bending Family Friendly into Fear:

Nostalgia, Minstrelsy, and Horror in Bendy and the Ink Machine

Copyright (C) 2019

by Isabelle Catherine Williams 


\author{
ABSTRACT \\ Bending Family Friendly into Fear: \\ Nostalgia, Minstrelsy, and Horror in Bendy and the Ink Machine \\ by Isabelle Catherine Williams
}

When one thinks of Disney's Mickey Mouse, fear and horror are not terms normally associated with this iconic American cartoon character; however, the video game Bendy and the Ink Machine turns animated bodies (cartoons) into bodies the player fears. In this game family friendly cartoon characters are transformed into figures of fear. Furthermore, Bendy and the Ink Machine does this by making the bending of Black bodies visible through what I call the gameic gaze. The transformation from family friendly into fear happens through the resistive gaze, the gameic gaze, which lingers on the bending of the diegetic cartoons. Bendy and the Ink Machine actualizes the historical contorting of the Black body starting in slavery and continued by the entertainment industry through bending. Bending and the Ink Machine makes the minstrel origins of cartoons visible through the gameic gaze. 


\section{TABLE OF CONTENTS}

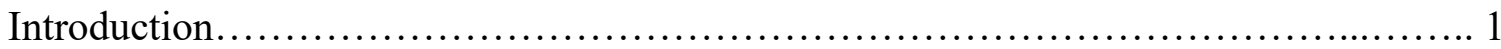

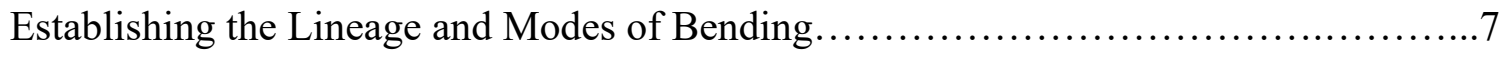

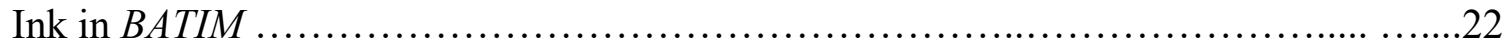

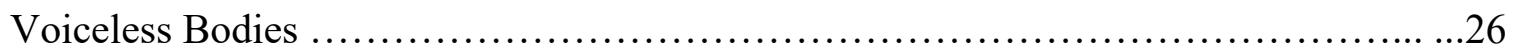

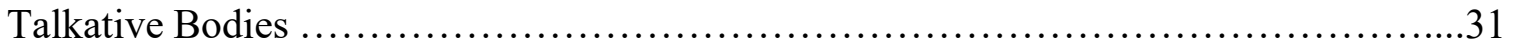

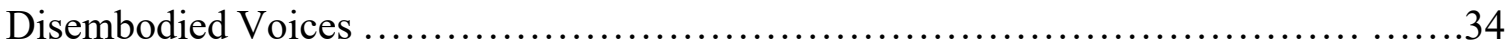

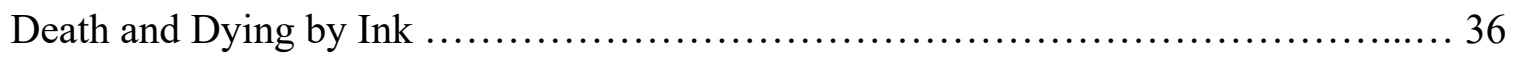

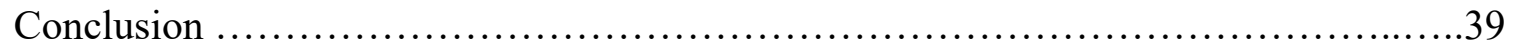




\section{LIST OF FIGURES}

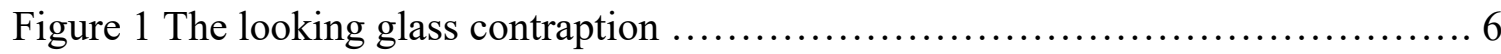

Figure $2.1 \& 2.2$ Lincoln Perry/ Stepin Fetchit in biological and animated form........ 17

Figure 3 Blackton drawing (Lightning Sketches 1907)............................ 18

Figure 4 The use of white gloves (Al Jolson, Mickey Mouse, and Bendy poster)........ 19

Figure 5 The White Glove Monster.............................................. 20

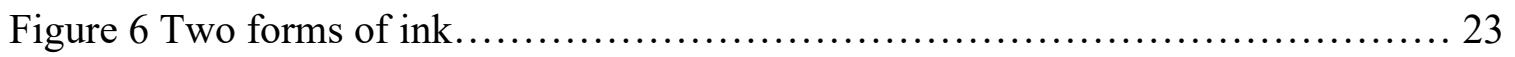

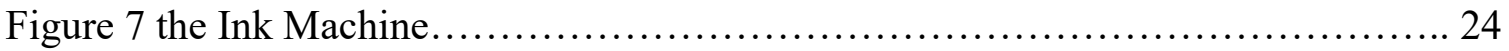

Figure 8 Mickey Mouse and Cartoon Bendy .................................... 28

Figure 9 Evolution of Corporeal Bendy .......................................... 29

Figure 10 Dissected Boris........................................................... 31

Figure 11 The multiple forms of Alice Angel...................................... 32

Figure 12 Sammy Lawrence with Bendy mask and without mask..................... 34

Figure 13 Unknown Audio Recording ........................................ 36

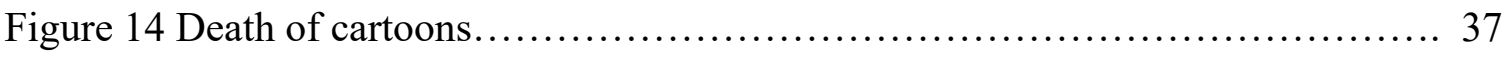

Figure 15 the Death of Bendy ....................................................... 38 
While films featuring biological bodies can be marketed for either children or adults, American animation was presented as a wholesome family friendly medium specifically for family units. The category of family friendly was not an accidental creation but a purposeful decision involving extra-textual techniques such as marketing, classification, rating, merchandising and broadcasting strategies (Brown 2012). The Walt Disney Company played a pivotal role in positioning American animation as a medium for children tasked with preserving 'childhood innocence' of the white middle class (Ratelle 2018). The primary way animation embodied this notion of family friendly was through the absence of explicit material displaying acts resulting in the excretion of bodily fluids such as sex and violence accompanied by blood (Brown 2012). That is not to say violence is completely absent from cartoons; rather, these animated bodies do not experience any permanent or harmful consequences because of the violent acts they endure. Instead of their bodies breaking, animated bodies contort and stretch while remaining playful. The playful tone is marked by the cheerful music, laughter of the characters and the lack of blood and death. American animation is packaged as family friendly yet these animated characters carry problematic iconography, such as white gloves, aligning cartoons to minstrel bodies; however, cartoons are not just similar to minstrels, cartoons are minstrels (Sammond 2015). Under this mask of playfulness, animation has sinister and hidden origins. Yet because of the family friendly façade of these bodies, this lineage between minstrels and American animation is an unacknowledged and unseen heritage.

Despite the invisibility of animation's problematic origins, resistive modes of looking exist within cinema for Black spectators. bell hooks examines the power of 
looking in relationship to Blackness by tracing the power of looking back to slavery when white slave owners punished slaves for looking (hooks 1996). Cinema offered Black spectators the first chance to look with intention, resisting the systematic regulation and lack of Black representation through the 'oppositional black gaze' (hooks 1996). This gaze reclaims the original trauma inflicted on Black slaves by using cinema as a way for spectators to look back at oneself and at one another (hooks 1996). Despite the existence and use of the 'oppositional gaze', American spectators are still learning how to look, to stare, at the legacy and replications of minstrelsy within American popular culture. The Black body, specifically its cinematic mutations, must be seen because the Black body has been problematically modified by cinema allowing these bodies to remain unquestioned within past and contemporary entertainment. The current types of looking do not yet allow or permit a gaze that highlights the historical and continued dangerous contortion of the Black body originating in slavery and continued in popular media.

The Black body is an object which has constantly been bent by the entertainment industry. The Black body began as a body with subjectivity and regulation; however, slavery removed the Black body from its subjectivity and replaced it with forceful and explicit regulation. The most overt example of the bending of the Black body is blackface minstrelsy. Minstrelsy can be defined as the white reimagining and projecting of the Black body onto white bodies. As America's first form of popular entertainment (Cole 2013), minstrelsy is a particularly dangerous form of performance. Minstrelsy fed off of the nostalgic longing for the "amusing" and "natural" days of slavery and used this sentimentality to structure blackface performances. With each "amusing" iteration of the Black body through minstrelsy, film, and then animation, the Black body has transformed 
from a body into a comedic performative object simultaneously resisting and enacting labor. By comedic performative object, I am referring to the objectification of the Black body as a source of entertainment reducing it to flesh, an object without subjectivity, disembodied from the body yet of the body. This use of the Black body as object was normalized and popularized through minstrelsy. Despite its explicit and overt misrepresentation of Blackness, minstrelsy has continued to be successful by obscuring the spectators' ability and willingness to see the contorting of Black body justifying this performance as amusing and playful. In order to see the continuation of minstrelsy in contemporary popular culture, an active looking equipped with knowledge about the historical regulation of the Black body is required; however, this type of looking must directly involve the participation of the spectator. While the historical significance and continuation of minstrelsy has been examined by previous scholars such as Eric Lott and Nicholas Sammond, I will be presenting the history of minstrelsy in a new way by locating this history within the space of play within videogames.

Unlike Hollywood cinema's directed looking, video games involve a mode of looking requiring an active participation of the user (the player and the spectator). The gaze in video games is still limited and constructed; however, the player is given the ability to move the camera, the eye, within the virtual world unlike cinema. The video game camera traditionally occupies two positions: First-Person Shooter (FPS), which aligns with the player with playable character's point of view, and Third-Person Shooter (TPS), which aligns the player with the "Other" traditionally associated with cinema. In video games, the movement and mobility afforded to the user by the 'CG-Eye' aligns the camera/mechanical eye and the biological eye of the player (Brooker 2009). The video 
game camera's dependence on the player for movement creates a type of gaze associated with the resistive power of hooks' "oppositional gaze." While scholarship on resistive modes of looking in cinema have been examined and established, there is a distinct lack of analysis on how the gaze manifests in video games. Due to this lack, I have created a new term to identify the resistive gaze used in some video games: the gameic gaze. I define the gameic gaze as an act of looking facilitated by the coded camera allowing the player to move and look without the same restraints as cinema; however, the gaze is also a liminal one because it is simultaneously of the body (the player) and of the machine (the computer). The liminality and player based machine constructed looking gives the gameic gaze a potent resistive potential to pressure the hegemonic presentation of Blackness in entertainment.

In the video game Bendy and the Ink Machine (2017), hereafter referred to as BATIM, the resistive potential of the gameic gaze is established and employed through the sensory based inversion of the nostalgic diegetic cartoon characters into horrific monsters. BATIM is a first person horror video game populated with cartoon characters. The game is about Henry, a retired animator at Joey Drew Studios, the only playable character, who is mysteriously summoned back to the studio by his friend and previous employer Joey Drew. Aside from gender, details such as race, age, and other personal identification are completely unknown. Even though the player never sees any part of the Henry, the player must still help Henry (and the player) escape the decaying Studio within the space of five episodic chapters: Moving Pictures, The Old Song, Rise and Fall, Colossal Wonders, and The Last Reel. Each chapter highlights a space, physical or economic or psychic, where the Black body has been further distanced from itself. 
However, all these spaces located in the studio are unified through a specific visual style. BATIM has a black and sepia color scheme creating a 'vintage cartoon' aesthetic emphasizing the fundamental animated form of all video games (Pallant 2018). Due to 'vintage cartoon' aesthetic, the gameic gaze of BATIM is explicitly located within the animated space, a liminal space that mimics its historicity. The liminal space of the gaze is further compounded by the inherent liminality of looking within a video game. As the player stares, the player looks through the eyes of Henry while simultaneously being both separate from Henry and aligned with Henry.

While the primary objective of BATIM seems to be for Henry to escape the Studio and survive, the game is actually about learning to see the sinister and hidden history of beloved animated figures such as Mickey Mouse. The concept of sight and the ability of the player/ Henry to see is directly built into the narrative as exemplified by the lookglass contraption - a device Henry acquires in the fifth and final chapter of BATIM. With this device, Henry is able to see previously invisible messages on the Studio walls. Henry/player must seek out and make the invisible visible in order to escape; however, this sight facilitated by the looking-glass is not a singular sight rather it must be repeated. In order for the player to locate all the hidden messages, the player must repeat the game after completing BATIM once. It is only through repeated play that all the secret messages can be read. Repetition is essential to the resistive sight; however, the looking glass device is only one way the hidden becomes visible. 


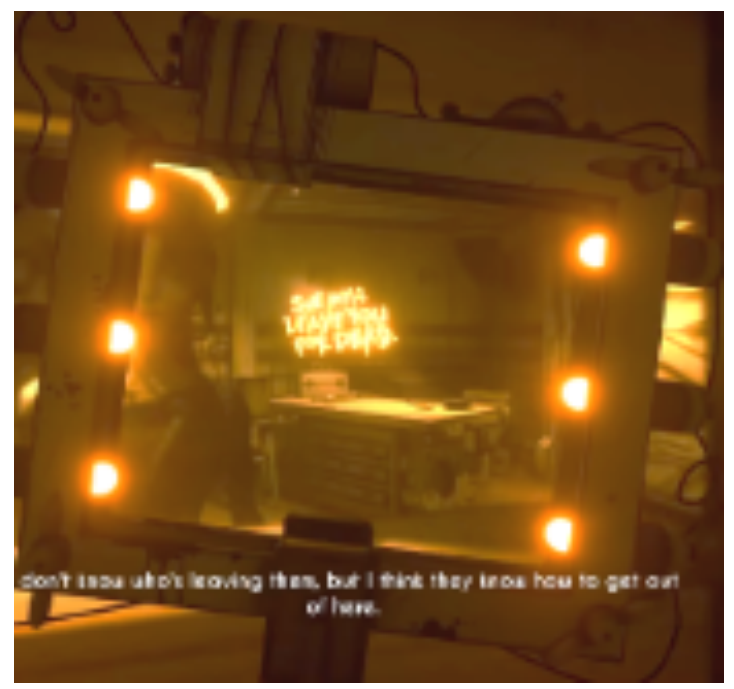

Figure 1: The looking glass contraption

The purpose of this thesis is to examine how the history of minstrelsy specifically its relationship to the voice and the body, both biological and animated, are revealed and resisted through the experience of play in BATIM. BATIM disrupts the problematic portrayal of Black bodies by directing attention to the horror associated with cartoon characters. In order to explore how BATIM transforms the minstrel iconography from nostalgic into horrific, this thesis will be divided into four sections: bending, ink, the body, and the voice. While scholars have examined the history of minstrelsy and its continuation in cinema, an explicit examination of blackface minstrelsy and video games not yet been explored; therefore, I created the term 'bending' in order to provide a framework encompassing the intersection between animation, minstrelsy and video games. Using my new term and framework 'bending', I will demonstrate the visual and auditory fracturing/disembodiment of the Black body continued by entertainment and how BATIM engages with this disembodiment. Just as minstrel performances distanced the Black body from itself through parading the white body as Black (Jones 2013), the animated body becomes distanced from itself: a fearful and violent process actualized 
through bending in BATIM. BATIM embodies the intersection between the problematic legacy of minstrelsy, the body as a regulated/governed form and a liminal object (mode of being) caught between entertainment and culture, and the voice as sound, verbal language (verbal expression) and identity. In order to use the resistive potential of a specific type of looking in video games, the gameic gaze, BATIM actualizes 'bendiness.'

Establishing the Lineage and Modes of Bending According to the Oxford English Dictionary (OED), 'bend' involves the alignment of objects between other objects or part-objects. 'Bend' is derived from an Old English term bendan which is thought to be related to the Old Norse term benda meaning "to join, strain, strive, bend" (OED 2019). The term 'bend' relies on movement/contorted object. Additionally, bending is a bodily act involving directing the gaze specifically an "inclination of the eye in any direction, glance" (OED 2019) as well as a turning of the mind. Bend is a directional and relational term involving outside force exerted onto an object such as a body. Therefore, bending is a movement and an object oriented term encompassing the primary concern of animation: the body.

Bending in BATIM is an act/action and a displayed process. The mechanical understanding of bend is directly connected to Black bodies. According to the $O E D$, bend refers to a mechanical apparatus of a cotton-spinning machinery specifically the "curved surface which sustains the chain of flats" (OED 2019) that separated cotton fibers. The cotton-spinning machine was created during the Industrial Revolution known colloquially as a 'Spinning Jenny.' The cotton industry in the United States was an industry powered by slaves. The Spinning Jenny did not diminish the use of slaves as labor objects; rather, the slaves' labor was reoriented to the machine. Black bodies became an extension of these cotton machines by fueling the machines through the act of bending their bodies in 
order to pick the cotton (Lakwete 2003). Therefore, 'bend' has a hidden reference to slavery and the oppressed regulation of the Black bodies.

Bending has been an explicit part of animation since its conception. Bending as an act and displayed process requiring a doubleness of the body and of form. Animation depends on repeated production of actual bodies; however, repetition is also a part of the doubleness of animation. The 'double sense' of animation directly involves plasticity of animated bodies, visual ambiguity, and double meanings (Hernandez 2008). Sight gags and visual puns are a primary part of creating the doubleness since there are two meanings hidden within a single act. The duality of animation also manifests as the repeated but slightly varied images of bodies used to create two dimensional movement on the screen. The regulatory qualities associated with the body become amplified through bending. In addition to exasperating the 'double sense' of animation, bending is also a mode of governmentality.

Michel Foucault defines governmentality in terms of its historical structuring and relation to the body. Foucault claims governing people (specifically children) through pedagogy originated in the sixteenth century (Foucault 2000). Since the body is an extension of the soul for Foucault, the disciplining of the body regulates the subject (the sense of self); one involving regulation/governing the body of the self as well as the bodies of others with the goal of being the best possible regulator/governor (Foucault 2000). Foucault identifies "three fundamental types of government...the art of selfgovernment, connected with morality; the art of properly governing a family, which belongs to economy; and, finally, the science of ruling the state, which concerns politics" (Foucault 206). From these three modes of governmentality, governmentality can be 
identified as an internal process (morality) as well as privately (the family) and publicly (politics) practiced. Foucault states "to govern, then, means to govern things" (Foucault 210) suggesting people and their bodies are reduced into things (objects) through governing. Governmentality removes the subjectivity of the body; however, the removal of subjectivity of the subject (the primary symptom) is to produce convenience. Foucault acknowledges the convenience factor in his definition of government "as a right manner of disposing things so as to lead...to an end that is 'convenient' for each of the things that are to be governed" (Foucault 211). Within governmentality, convenience means a "proper" alignment with hegemony. Convenience is conformity. To govern means to regulate the body; therefore, the object of regulation is the body.

In addition to the body being the object of regulation, the body is also a product of culture. In Unbearable Weight: Feminism, Western Culture and the Body, Susan Bordo defines the body in relationship to culture by borrowing Foucault's term 'docile bodies.' In the original use of the term, Foucault examines how the soldier's body is made docile through discipline manifesting in attire/costumes, bodily gestures and diction. A body is made docile/malleable through discipline, the 'docile-utility.' Bordo uses Foucault's 'docile body' and applies it to the daily rituals of women such as dressing and eating. Bordo identifies the female (feminine) body as a 'docile body' because these are "bodies whose forces and energies are habituated to external regulation, subjection, transformation, 'improvement'” (Bordo 2241). These live 'docile bodies' are regulated primarily through repeated images. Similarly to how the female body is made 'docile' through internalization of external images in order to 'improve' said body, the Black body is made 'docile' through repeated problematic images of Blackness as lazy and 
infantile perpetuated by the entertainment industry.

While minstrelsy and its use of blackface has been thought of as a performance of the past, minstrelsy is still a very present part of contemporary popular culture largely because of the purposefully unseen markers of minstrelsy these forms of entertainment still carry (Sammond 2015). Minstrelsy originated as an imitation of slave performances in New York markets (Kootin 2013). Since slavery legitimized the regulation of the Black body for labor, minstrelsy legitimized the regulation of the Black body as an entertainment object. Minstrelsy is an explicit bodily borrowing of imagined black culture for white consumption which problematically confirms slavery as natural, right, and entertaining (Lott 1993). Without the Black body, minstrelsy would not exist. One of the most prominent features of minstrelsy is the use of the burnt cork mask. In order to create the burnt cork mask, burnt and mashed champagne corks are mixed with water or a petroleum jelly substance and placed on the white face as makeup (Mahar 1999): a process known as "blacking up." The burnt cork makeup explicitly exemplifies how Black bodies were remapped onto white bodies by marking of white bodies with blackface. "Blacking up" the white body worked as a ritual demonstrating the hegemonic governing of the body. Through this marking, the performers become objects of regulation and the burnt cork is a mask (and as makeup) signaling this regulation. In addition to having a distinct deep black color, the burnt cork make up also had a greasy and sticky texture due to the layer of grease (or cream) worn under the makeup (Post 2015). This 'blacking up' process depends on the textual stickiness of the burnt cork make up.

By the term 'sticky,' I am referring to Sara Ahmed's concept of 'stickiness.' In 
Ahmed's exploration of how happiness relates to biological bodies, she states "affect is what sticks, or what sustains or preserves the connection between ideas, values, and objects" (Ahmed 29). According to Ahmed, "happiness can generate objects through proximity [through the] 'hap' of happiness" (Ahmed 36). While etymologically 'hap' is connected to chance, the 'hap' of happiness involves a cultivated intentionality protected and practiced by individuals. 'Hap' is also about the distance (proximity) to happiness. The 'hap' of happiness suggests a cultivation, a curating of the object alongside the body. Ahmed's concept of stickiness arose from this idea of 'hap' because stickiness refers to the actual process of transference from body to body via affective objects. Affect is sticky because of the bodily alignment and transmission but without suggesting a causation, or an origin, of this movement. Stickiness involves a promise of a certain bodily alignment to an object (Ahmed 2010). While it seems this concept of "sticking" is aligned with a protective, sustaining, and preserving process, there is a darker side to stickiness. Stickiness preserves and connects while simultaneously contaminating bodies; therefore, stickiness is an invasive and invisible process saturating bodies.

Just like happiness, minstrelsy is sticky. The stickiness of minstrelsy is derived from its prevalence facilitated by a nostalgic justification; however, minstrelsy does not just persist in popular culture, it goes through undetected. The invisibility of minstrelsy is derived from this performance's connection to nostalgia. In addition to cloaking contemporary minstrelsy in popular culture, minstrelsy's stickiness is symptomatic of the nostalgia embedded within the performance itself. While nostalgia is traditionally thought of as a longing for the past, the postmodern understanding of nostalgia is as a political motivation reflecting the current state of society (Jameson 1969). Nostalgia is a longing 
for a false past and this longing reflects how contemporary society views itself. The fallacy of minstrelsy (the false displayed Black bodies) aligns with the problematic sentimentality of nostalgia through the repeated bending of the Black body.The practice of minstrelsy in the eighteenth and nineteenth century was already a practice of nostalgia because this performance involves an auditory and visual longing for the slavery days: a longing augmented when minstrel performances became a part of the film industry. The nostalgia embedded within animated bodies of 'cartoon minstrels' is one transmitted via the visuals and sounds used in cartoons.

Minstrelsy created a largely invisible division between actual living Black bodies and those displayed on screen. The division between the actual and the displayed Black body can be aligned to the division between the True and False Self identified by D.W. Winnicott. The True and False Self are psychoanalytic terms describing the unconscious internal division of the Self. The False Self, the projected and displayed self, has a defensive function "to hide and protect the True Self, whatever that might be" (Winnicott 142). The False Self always exists as does the True Self; however, the relationship between these two terms is crucial to understanding how personalities form and function. While Winnicott is primarily interested in the development of the Self (particularly the role of the mother in this development), the defensive nature of the False Self and the hidden nature of the True Self mirrors the fracturing of the Black body by the entertainment industry. The Black body is the actual biological body while the displayed Black body is constructed by entertainment is a false projection. Minstrelsy fractured the Black body into consumable parts while simultaneously presenting a representation of Blackness as true; therefore, the division between the False Self and the True Self 
becomes an externalized performance. Minstrelsy buries the True Self (the Black self) and only legitimizes the False Self (the caricature, the coon, and the trickster); therefore, minstrelsy parades the False Self as the True Self.

The regulation of the body particularly the Black body was intensified through the advent of the Production Code. The Production Code (1930), derived from the Don't and Be Carefuls (1926), was created by the film industry in an attempt to avoid state and national censorship as well as public outcry. The Production Code determined what cinematic content qualified as appropriate for different types of audience; however, the Code was particularly invested in regulating films for children and families. Since the Code was connected to the Legion of Decency, a Catholic organization formed in 1934 (Vaughn 64), family friendly content meant conveying a Catholic moral narrative. As a Catholic organization, the Legion of Decency swore to "boycott offensive films" (Vaughn 64) and in turn defined the qualifications of the offensive film. The Legion of Decency worked together with Joseph Breen, the head of the Production Code Administration (PCA) to define family friendly as well as qualities of offensive cinema. The primary objective of the Code became to maintain childhood innocence by regulating cinematic images.

The family-friendly bending of the Black body allowed for the continued regulation and repression of the Black body. The lack of concern for how the Black body was presented, as long as the body was secondary to the white protagonist, highlights the expected and accepted use of Blackness. For example, when Hedda Hopper leaked a rumor about an alleged less than favorable performance of Stephen Foster in the Fox film Swanee River (Sidney Lanfield 1939) a flood of public outcry followed. These letters to 
the PCA begged for the preservation of Foster, a minstrel music composer, as a historical figure respected by children. One letter from a protestor named Nancy Campbell stated "I protest the release of the picture 'Swanee' in which [the] script calls for him [Foster] to be inebriated in nearly every scene. This emphasis will smear his name in the eyes of American children" (Nancy Campbell to John Hayes, 3 October 1939). Campbell positions the fear of smearing Foster's name (she means the nostalgia associated with Foster) as the absolute "crime" against the American children. While the other letters in this PCA file share a similar sentiment, none of the letters contained outcry for the use of blackface in the film. These letters demonstrate the power of the family friendly facade and the acceptance of blackface as a legitimate and unquestioned part of the entertainment industry. Additionally, these letters demonstrated how innocence and family friendly become problematically conflated through cinema. The conflation of between innocence and family friendly are particularly evident in early American animation.

While the façade of family friendly has broken down in recent years with unapologetic animated television shows aimed at adults such as Rick and Morty (Roiland and Harmon 2013) and Bojack Horseman (Bob-Waksberg 2014), the early American animation industry, especially Disney animation, positioned the animated space as a place and creator of dreams. The primary way American (children's) animation used dreams both as space and ideology was to cultivate and maintain the qualities of childhood innocence. In order for animation to remain innocent, it must align with the hegemonic constructions of childhood as an idealized state of being divorced from reality, a dream like state of development. The didactic function of animation established 
by Disney films supports "an ideologically conservative worldview based unquestioningly on a narrow, hegemonic interpretation of middle [white] American values" (Whitley 76). American animation's capitalistic power is derived from its fetishization and cultivation of childhood innocence: a mode of being reserved for childhood unappreciated by children and longed for by adults (Whitley 2013). The use of innocence in family friendly animation depends on the limited understand of "childhood innocence as simply a symptom of adult nostalgia" (Whitley 77) because this understanding of innocence does not allow for the transformative power of these narratives to be realized. Rather, the ideology of dreams, the space of dreams, becomes synonymous with childhood innocence.

In American culture, the term 'dream' has a decidedly capitalistic history and implication especially when it is considered alongside the American Dream, the ideology of Americans; however, this dream is one intertwined with the Black body as a labor and an entertainment object. In Facing Up to the American Dream: Race, Class, and the Soul of the Nation, Jennifer Hochschild defines the American Dream as "a new world where anything can happen and good things might" (Hochschild 17). The American Dream has specific tenets of success and regulations regarding who may achieve said success (Hochschild 1995). The American Dream only acknowledges the dominant white population as dreamers. Animation repeats this understanding of dreaming as limited with tenets and practices this ideology within the enclosed animated space. Dreaming is a space, an act and a capitalistic qualifier of success. Just as the American Dream (material wealth and status) is mythos of America, dreaming (childhood innocence) is the mythos of children's animation. The magic of animation, the dream of animation, is that "any 
object in an animated world has the potential to come to life, and any living thing or even one of its body parts may be reduced to an object" (Sammond 234). Magic and dreaming of animation is simultaneous possibility of subjectivity and commodification of the cartoons. The ideology of cartoon (dreaming) is the ideology of capitalism (the American Dream). The American animation industry as an extension of capitalism is demonstrated by the extra-textual objects, the commodities, created beyond the actual animation. For example, the cartoon characters are sold as toys, the setting of animation become theme parks, and the animated films become animation television shows. Animation is a cycle of production both outside and within the diegetic world of the animated space. The inclusion and repeated use of the problematic 'Black Voice' in cinema exemplifies how the animated space is an internal site of production and commodification.

Miriam J. Petty defines the 'Black Voice' when discussing Lincoln Perry's problematic stardom as Stepin Fetchit in the 1930s. Perry/Fetchit's voice was how he entered Hollywood; however, his voice also limited the roles he and other Black actors played to the uneducated, unintelligible trickster and other "amusing" caricatures. The 'Black Voice' is a voice with oppressive origins limiting Black actors to stereotypical and problematic roles (Petty 2016). The drawl of his voice and nonsense words he produced mirrored his slumped and lazy postures reinforcing the images of Blackness perpetuated by minstrelsy. Perry/Fetchit's 'Black Voice' also extended into cartoons such as Disney's Broken Toys (1935) and through this connection the 'Black Voice' became an explicit part of the 'aural imagery' of Disney animation (Telotte 2008). 

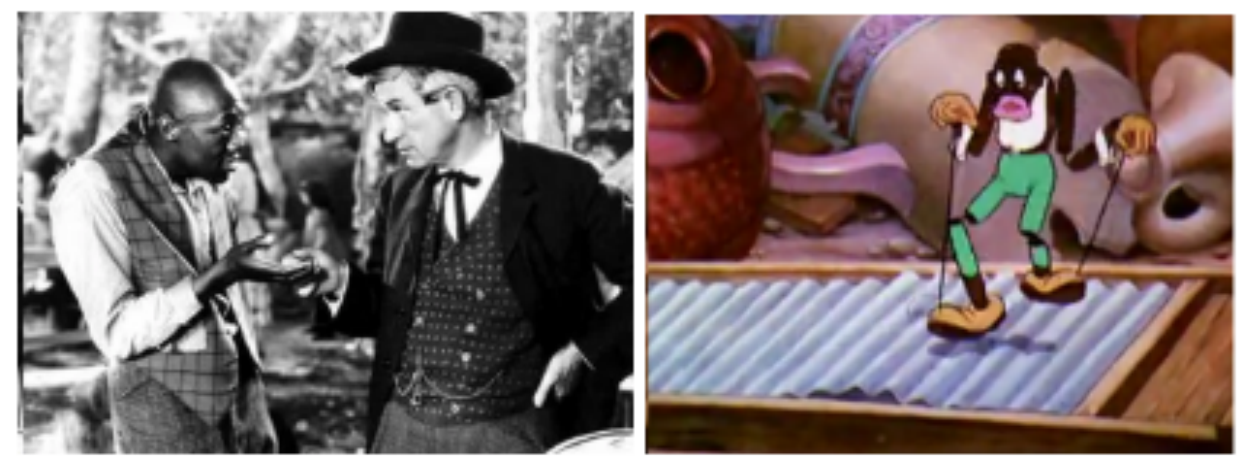

Figure $2.1 \&$ 2.2 Lincoln Perry/ Stepin Fetchit in biological and animated form

Telotte defines 'aural imagery' as the soundscape including noise, music, and voice, as the auditory makeup specific to animation used to heighten or build up to a comedic moment. The verbal expression and the overall soundscape was another way to govern the Black body, live and animated. As BATIM is a horror video game, the diegetic soundscape is essential to creating horror-play. There are three auditory components of BATIM's soundscape: 'aural imagery,' music, and the voice specifically the 'Black Voice.' While 'aural imagery' is traditionally sound used to create comedy, BATIM uses 'aural imagery' to create horror.

As demonstrated by Nicholas Sammond in Birth of an Industry (2015), animation provided another space to distance the Black body from itself. Sammond explores why animators used minstrels to build the American animation industry. He uses two terms to identify the lineage between live minstrel performers and animated cartoons: 'vestigial minstrels' and 'cartoon minstrels.' 'Vestigial minstrels' carry tokens and performative behaviors associated but not signifying minstrelsy while 'cartoon minstrels' are actual minstrels (Sammond 2015). The primary difference between these two terms is 'vestigial minstrels' are passive while 'cartoon minstrels' are active. The activity of the 'cartoon minstrels' can be seen in the use of the hands. As is shown by early films featuring 
animation such as Lightning Sketches (Blackton 1907) animation cannot be removed from the hand of the animator. Blackton begins this film drawing a "coon" from the written word "coon." The word becomes hidden within the face of the cartoon "coon" embedding the word within the body of the minstrel. The hand uses the problematic word 'coon' to label, identify, and structure the body of the minstrel. The title of film also refers to a mode of performance known as lightning-sketch "a performative tradition in which the live performance of animation centered on the animator's deft hand as the locus of skill and transformation" (Sammond 247). The use of the animator's hand in early animation also highlights "the animated character both as living and as made" (Sammond 247). The animator's hand disrupts the suspension of disbelief by drawing attention to the construction of both the cartoon and the film (or live performance).
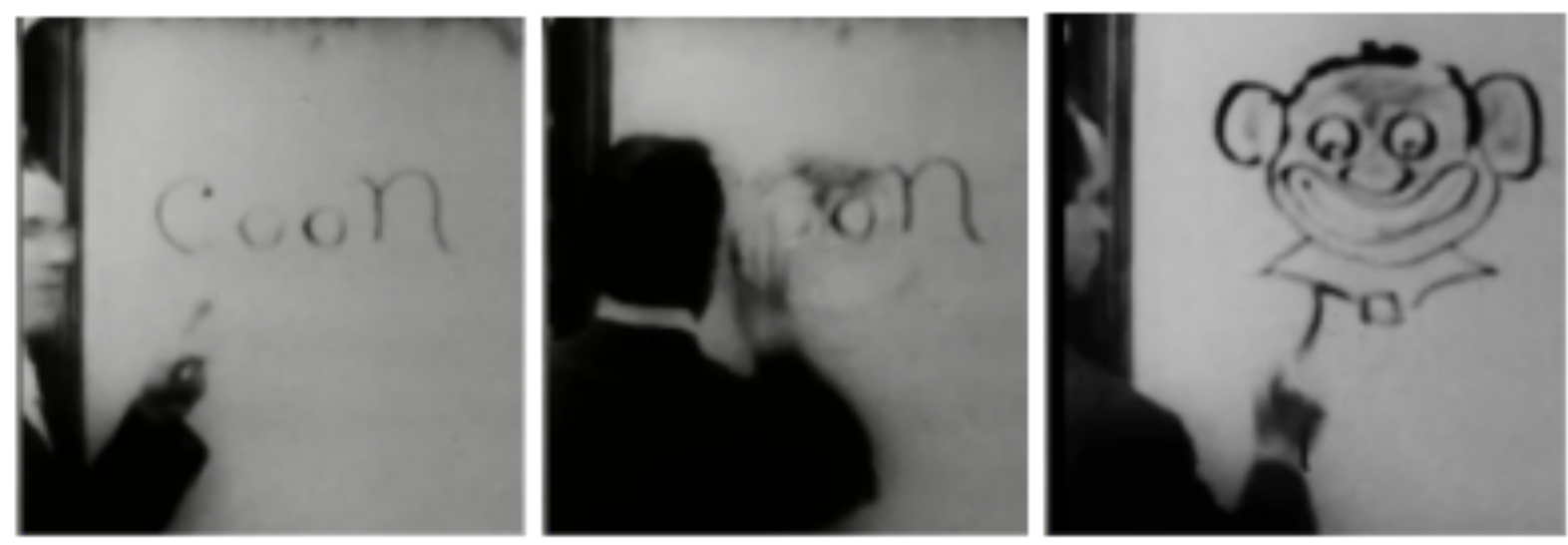

Figure 3: Blackton drawing (Lightning Sketches 1907)

Hands are an essential part of the process of animation as well as the animated. The white gloves are motifs of both minstrels and animation; however, these white gloves are more than an aesthetic choice. For minstrels, the white gloves are an amusing façade of white gentile manners mocking the notion of class mobility and racial tolerance 
(Sammond 2015). Additionally, the white gloves are a purposeful recall of the white master's hands. One of the most common motifs in animation are the characters wearing white gloves, the same type of gloves worn by live minstrels. Figure 4 illustrates the white gloves as a direct and visible connection between live minstrels and 'cartoon minstrels.'
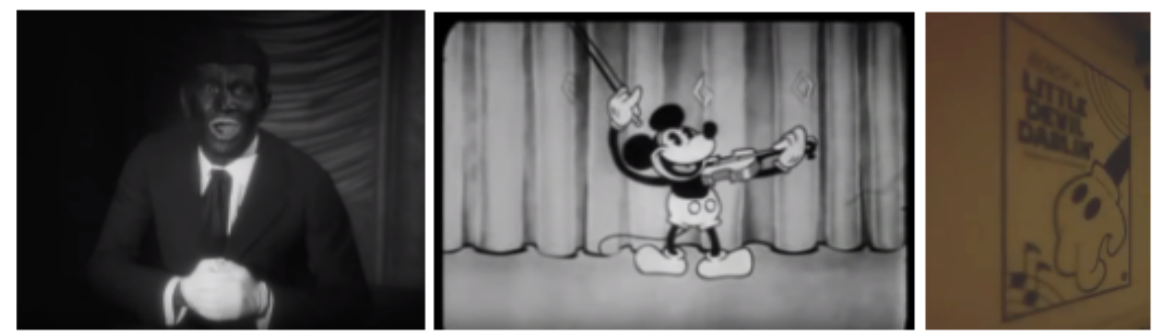

Figure 4: The use of white gloves (Al Jolson, Mickey Mouse, and Bendy poster)

While white gloves were part of the "amusing" blackface iconography passively signifying class and racial tensions, the white gloves have an undeniably sinister presence in BATIM. In the fifth chapter, the player/Henry must navigate the Ink River where a white gloved monster is located. This is the only time the white gloved monster appears. Only one hand of the monster is seen during this part of the game, much like the one hand of the animators such as Blackton. This large gloved hand pulls barges into the Ink River; therefore, the hand is an object of destruction. Knowing the lineage of the white glove from minstrel to cartoon minstrel, this destructive and even more oversized white glove is a purposeful signifier of the destruction this symbol represents. The cartoon characters in BATIM are 'cartoon minstrels' that frighten rather than entertain. As represented by the white gloved monster, the 'cartoon minstrels' of BATIM amplify the hidden connections between animation and minstrelsy by making the makers of minstrelsy visible through by reorienting these playful objects into objects of fear. 

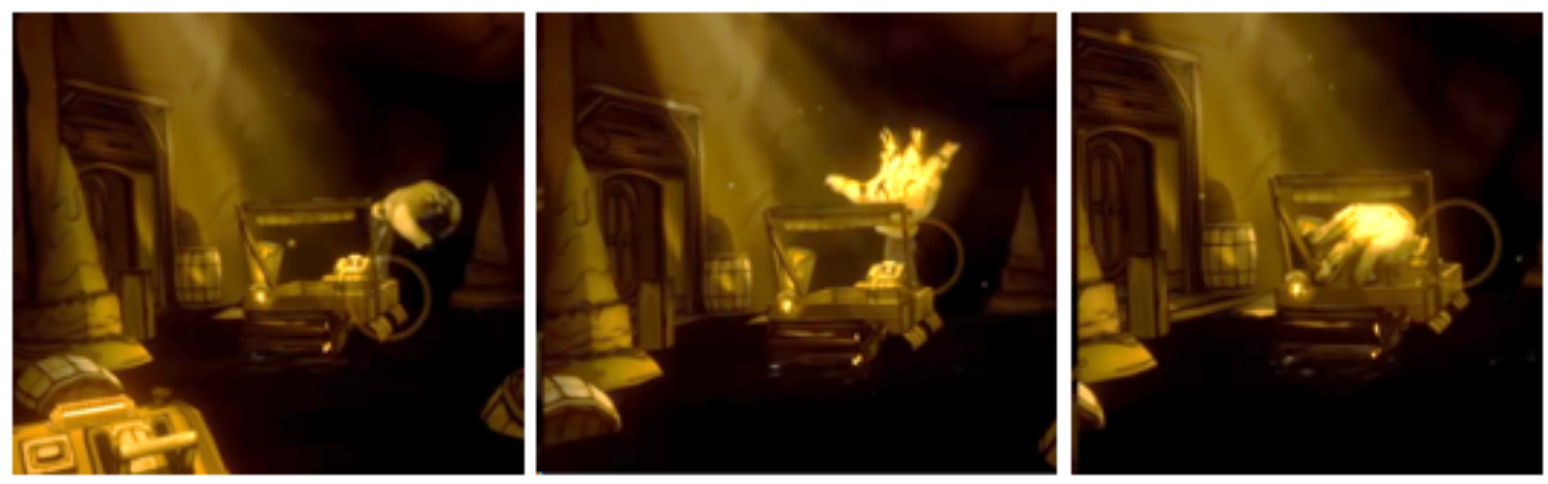

Figure 5: The white glove monster

While play is a difficult term to define because of its inherent ambiguity (SuttonSmith 1960), play can be identified as an inseparable part of animation since the process of animation is the process of play (Pallant 2018). Just as play is limited within the workings of the 'magic circle' (Huizinga 2014) or the frame where play can be acted, the process of animation occurs and moves within a frame defined by the hand of the animator (Pallant 2018). Play can be defined as the potential for freedom but is still restricted by the frame where play occurs (Pallant 2018). Play is an unbound practice and/or display within a bound space. The concept of play is amplified in animation, an amplification which becomes augmented through the inclusion of the player in video games. Just like with animation, the play associated with video games can only occur within a given frame, a 'temporary world' (Pallant 2018). In BATIM, the bendy bodies themselves are playful while simultaneously requiring play; therefore, play is both an action and a display (Galloway 2006).

Another essential quality of play is repetition. The process of animation, is the process of repetition. Similarly to animation, video games depend on a repetition beginning with the repeated reading of a machine. In video games, play requires a player, 
someone engaged in play; however, play is a unification of two types of actions: 'operator actions' and 'machine actions' (Galloway 2006). 'Operator actions' are decisions made by the player while 'machine actions' are software and hardware decisions (Galloway 2006). The player is not the only source of play. There is another language at work in video games: the language of code, a language distinguishing video games from other media. According to Galloway, "code is the only language that does what it says" (Galloway 5) because code is syntactic, semantic and mechanic. It is a language requiring, expecting, and directing clarity in spaces. Code as a computer language is dependent on repetition and varied repetition for clarity. The space of the video game, the space of virtual play, emerges from the machine's repeated reading of code and displaying the language. Play within video games is dependent on the mechanical reading of code. Play is not just an outward/external display, but it is also an internal processing, a hidden yet essential language.

Play also complicates and amplifies bending as an act in BATIM. Since all the antagonistic characters are cartoons, play is present in this video game even before the player engages with the game because animation itself is a type of play. Play manifests in animation through two specific terms: lichtspiel (light play) and 'plasmaticness' (Power 2012). While lichtspiel refers to the use of artificial technological light to create images, light can also be thought of the traditional perceived tone of animation since play is often thought of as light, the opposite of seriousness. Additionally, cartoons have a 'plasmaticness,' the lack of a single form, recalls how each cartoon body is formed from multiple different stills of the body. However, the 'plasmaticness' of animation becomes a fracturing process recreating distance between the cartoon and the biological form all 
cartoons are based on: the Black body.

The multiplicity created by 'plasmaticness' is further augmented by the multiplicity of play via the player. When the player begins to play the game, play becomes an act facilitated by the player; however, the player use a specific type of play which I will call horror-play. Horror-play is a player based play using fear as a type of resistance. There are several layers of play present within this game. Streaming platforms have afforded yet another way to play this game through the phenomenon known colloquially as the play-through (located on streaming platforms such as YouTube and Twitch) where gamers play the game and people watch the game being played by another instead of playing it themselves. This play, which I will call facilitated-play, a passive type of play because the spectator is not involved in act of playing. Bending is dependent on this multiplicity of play because without engaging in play, the bending is not witnessed. The multiplicity of play creates a multiplicity of access point into the space of play. From this multiplicity, the space of play allows for bending.

\section{Ink in $B A T I M$}

Within the video game, ink actualizes bending while simultaneously signifying the process of producing animated bodies. Animated bodies would not exist without ink. Since cartoons are minstrels, the black ink used to create these cartoons is "a distillation of the qualities of an ideal blackness that began formless" (Sammond 108). From the viscosity and bending quality, "ink was represented as the essence of their being and of the blackness of their material base" (Sammond 108). BATIM uses ink, a thick black liquid, to locate and actualize the sticky lineage between minstrelsy and animation through the BATIM characters. The diegetic ink in BATIM appears in every part of the game. The diegetic ink within and surrounding the bodies of BATIM is the only liquid 
present in the game. The ink itself appears in two forms: a dried solid outlining the bodies of drawn cartoon characters and a thick black liquid. The primary difference between these two forms besides their state of being is the solidified ink is passive while the black thick ink is active. The activity of the black thick ink manifests as a stickiness. In this way, Ahmed's notion of stickiness transcends the narrative of game and bleeds into the actual play of the game. The second form of ink becomes a signifier, a visualization of how the body is molded. Through its stickiness and pervasiveness within BATIM, the second form of ink is a twenty first century signifier of minstrelsy in terms of consistency and the way which ink forms and clings to the body of the monsters. When I refer to ink throughout this paper, I am specifically referring to the second form of ink because this ink signifies the intersection between minstrelsy and animation.
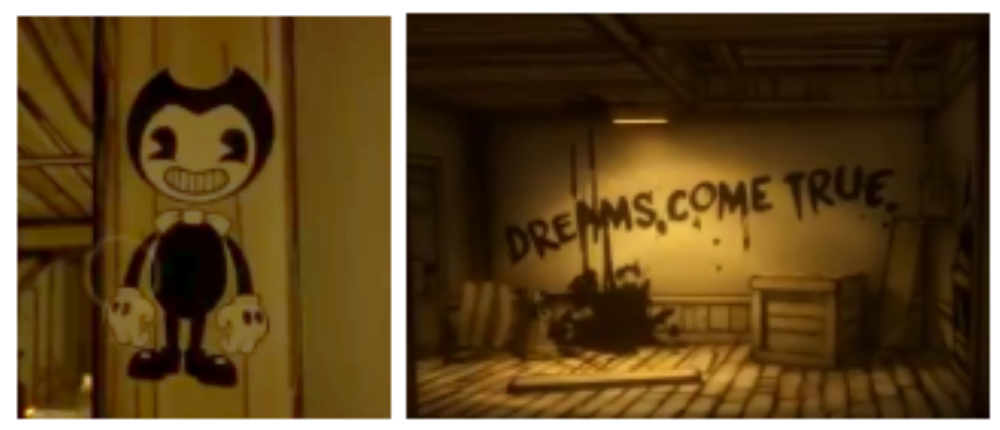

Figure 6: Two forms of ink

Ink also has an explicit mechanical origin connecting the diegetic ink to industrial production. The structure and ordered production of ink highlights ink as mode of regulation, a mode of production. The first objective in BATIM is to find the mysterious Ink Machine, commissioned by Joey Drew and created by technology company, Gent. The function of the machine is to pump ink to power the studio and create what Joey Drew refers to as "living attractions." All the objects in BATIM are dependent on ink for power and movement. Ink powers the Studio, bleeds from the monsters, is the source of 
monsters, and drips from the ceiling. Due to its movement, the ink also acts as an obstacle, preventing passage and movement by flooding and blocking pathways. Through gameplay, the player is conditioned to fear the cartoons covered in ink. Ink is the source of biological and mechanical power (active), the site of fear (antagonistic), the source of monsters (antagonistic), and the mode of regenerating both life and tools (productive). Ink is not a static signifier; rather, ink is active in BATIM. In the game, ink is both a bodily form of the characters and a written language displayed on the walls of the Studio.

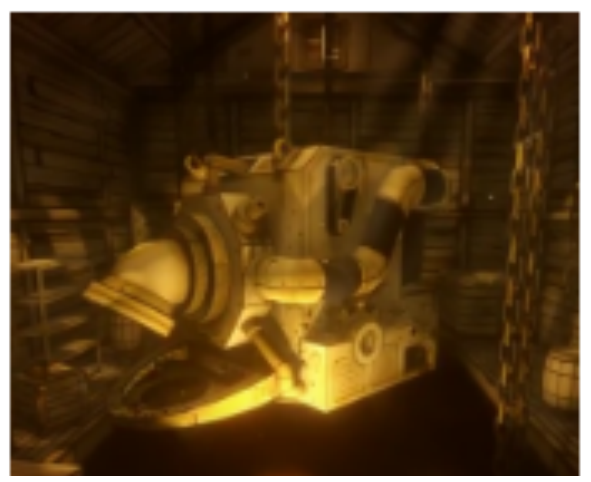

Figure 7: the Ink Machine

Ink is also a specific written language used to highlight the tension between the remembered (visible) history and the hidden (invisible) history of animation. The visible history of animation is represented by a book by Joey Drew called Illusion of Living (a book Henry must retrieve in order to fix the Ink Machine's flow of ink). While the contents of this book are never shown, the title is a clear reference to Disney animators Frank Thomas's and Ollie Johnson's Disney Animation: The Illusion of Life (1981), later re-published as The Illusion of Life: Disney Animation (1995) (Pallant 2011). In this ubiquitous text about the craft of animation, Thomas and Johnson outline twelve mechanical techniques Disney animators used to establish 'realism' which can be collectively classified as pose-to-pose animation (Pallant 2011). Unlike the other dominant mode of animation known as straight ahead action involving the spontaneous 
work of an animator from start to finish, pose-to-pose animation is a highly industrial process involving the lead animator tracing the dominant actions of the character and then an assistant filling in the missing movements known as 'inbetweens' (Pallant 2011). The use of the 'inbetweens' emphasizes the fragmented quality of pose-to-pose animation because this process emphasizes efficiency over spontaneity. From the repetition of 'inbetweening,' "the cartoon minstrel was an embodiment of this rapid rationalization, an avatar of alienation" (Sammond 240). Animation becomes a product alienated from its labor. Additionally, the inclusion of 'inbetweens' alludes to the broader concept of liminality. As Bjorn Thomassen notes in "The Uses and Meanings of Liminality," liminality is "any 'betwixt and between' situation or object" (Thomassen 16). The process of 'in-betweening' creates liminality within the animated character in terms of movement and production. In order for the bodies to animated, they must be divided into multiple yet slightly varied bodies. However, the distance created by this embedded liminality of animation is not the locus of the official history of animation.

While Joey Drew's Illusion of Living is an artifact of the animation's official history from the perspective of the animators, the ink writings on the wall also provide an incomplete and unofficial history of Joey Drew Studios from unidentified cartoon characters. The first ink message Henry encounters states "Dreams Come True" referencing the dream mythos of animation perpetuated by Disney. These ink messages counter the magically/playful and happy associated with dreams. The second message found states "Who is laughing now?" Dreams become a curse through the ink writings. Although the player/Henry never sees who has written all the messages, we do see a protagonist form of Alice Angel in the fifth chapter writing on the ink messages while we 
are locked in jail. This moment hints that the cartoons, whether that be just protagonistic Alice Angel or others, have been the ones writing the messages.

In addition to being a written language, ink is inseparable from the cartoon bodies specifically the bodies of Bendy, Boris, and Alice Angel. If the body is not directly saturated in ink, the player does not see the body. In other words, the body must be regulated in order to be visible within BATIM. For example, the player never sees the body of Henry because his body is not directly produced by ink. The lack of Henry's body, even his reflection and limbs, places all the focus on the displayed animated bodies. The objects of the gameic gaze are the contorted bodies of the cartoons that only have the power/ability to destroy. The supersaturation and pervasive presence of ink in $B A T I M$ allows ink to become a signifier and visualization of regulation. Not only does ink construct the bodies of the cartoons, ink also writes how the bodies are to be viewed. Foucault's identification of the body as the site and method of regulation/governmentality means the bodies of BATIM must be examined because their heavily regulated bodies (as demonstrated by the excess of ink) are attempting to make governmentality visible. The objects of the gameic gaze are the bodies of the cartoons and the process of bending each cartoon body is subjugated to.

\section{Voiceless Bodies}

While Mickey Mouse is one of many 'cartoon minstrels,' Mickey's legacy and form is referenced throughout BATIM; however, the reference to Mickey is purposeful because of his continued prevalence in American culture. On the surface, Mickey Mouse is a partially clothed anthropomorphic mouse with a playful disposition, yet upon reexamination, a more problematic origin of Mickey emerges - one possessing a 'sticky' legacy. Mickey has a signature look which is repeated in almost every cartoon he appears 
in: white gloves, blackened body, large shorts and oversized shoes. His repeated outfit is the same type of outfit worn by live minstrel performers predominately the white gloves; however, Mickey's minstrel origins extend beyond his costume. Mickey is historically significant to animation history because Mickey appears at a moment of transition within the film industry - the transition from silence to sound. This transition immortalized Mickey as one of the first successfully sound cartoons. As noted by Sammond, "Walt Disney Productions' Steamboat Willie (Disney 1928) looms large...as the landmark for the introduction of synchronous sound into the animation industry" (Sammond 117). The transition to sound meant animation, "which had at that point a long - standing convention history of celebrating its own performativity... disvow[ed] it's vaudevillian roots and obscur[ed] the actual labor of cartooning" (Sammond 120). Before Mickey and Steamboat Willie, cartoons such as Ko-Ko and Felix used the "vaudeville aesthetic...the self-referentiality [associated with] the lightning-sketch" (Sammond 114). Sound was the first moment the labor and the origins of cartoons became distanced from the actual cartoon form. In addition to emerging during the transition to sound, Mickey is also voiced by Walt Disney. Mickey is not just a cartoon; he is a nostalgic object signifying the importance of Disney Studios in the animation industry. Mickey became a part of mythic creation myth exemplifying the innovation and creativity of Disney. BATIM takes up the power of Mickey and pressures his nostalgic power within American popular culture through Bendy, the main antagonist of BATIM. 

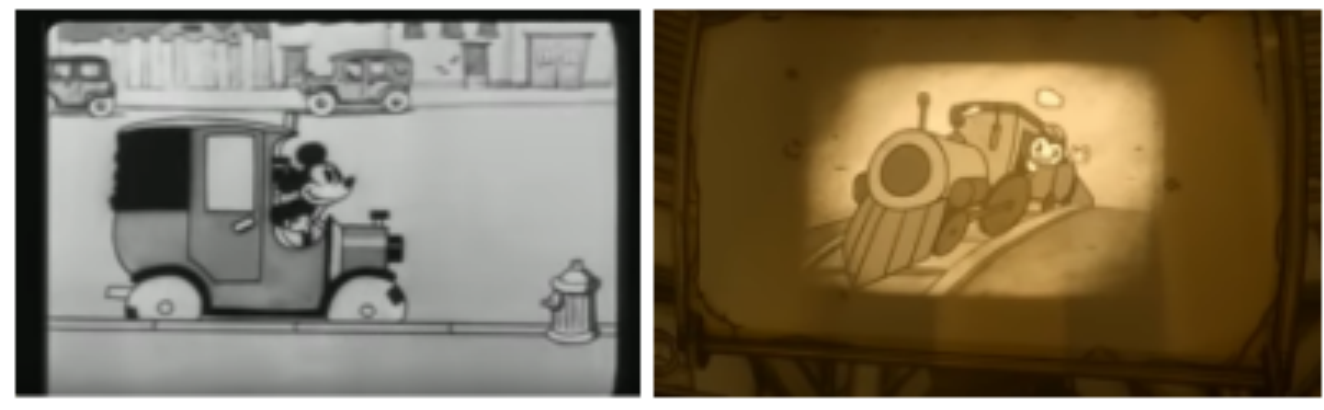

Figure 8: Mickey Mouse and Cartoon Bendy

Within the diegetic world of BATIM, Bendy occupies the same mythic status Mickey occupies in contemporary culture; however, Bendy's status becomes one of fear. While Mickey's mythic status is demonstrated through his place in animation history and his continued presence in American culture, Bendy's mythic status is demonstrated by the saturation of Bendy's image throughout the Studio. Bendy has two forms: his cartoon form (cartoon Bendy) and his evolving corporeal form (the Demon); however, these two forms occupy the video game space differently. Bendy's cartoon form appears in posters, sketches and pictures throughout the Studio; however, there is only one Demon. The Demon is the cartoon entity hunting the player/Henry. As shown in Figure 9, the Demon evolves throughout the game from a corporeal cartoon Bendy into a large ink monster with sharp teeth. The doubleness created by Bendy's two forms acknowledges the 'double sense' of animation "the duplication of a virtual image... a conceptual movement that calls attention to the surface of representation, instead of its actual contents" (Hernandez 1). Bendy's doubleness creates an omnipresence fear that Bendy will appear and attack the player/Henry. The "double sense" of Bendy's body creates discomfort in the form of fear and tension. While Bendy's body is a powerful narrative object because of his pervasive presence, Bendy is voiceless throughout the game. Bendy's lack of voice 
is similar to Henry's lack of body: the focus is on Bendy's bodily consumption via ink and his lack of subjectivity, his lack of voice.
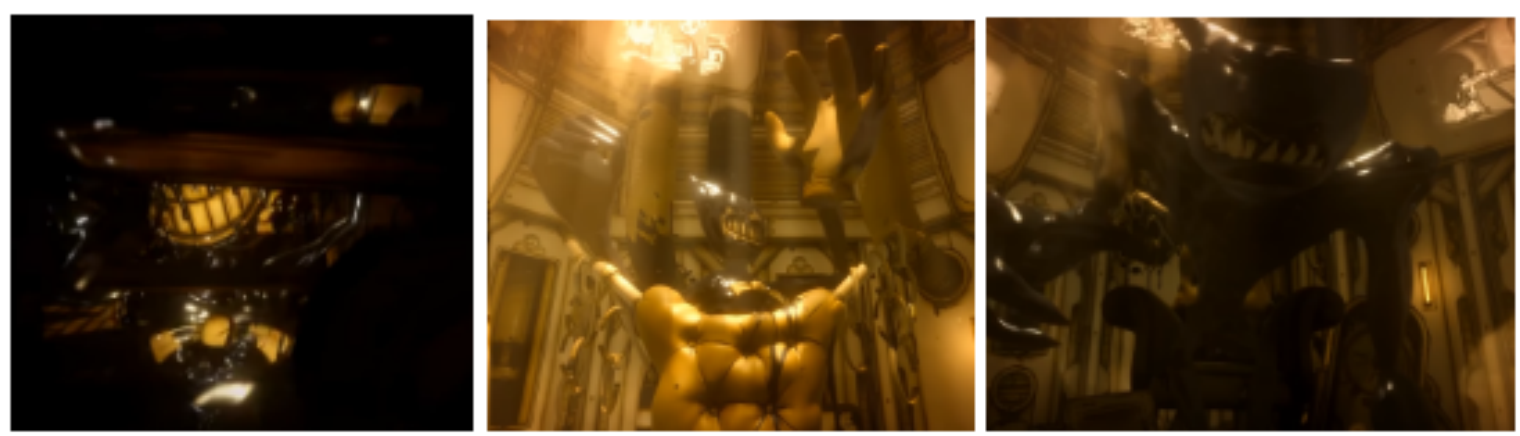

Figure 9: Evolution of Corporeal Bendy

Another voiceless body is Boris, a mostly protagonistic cartoon character who accompanies Henry, whose body is continuously bent through the game invoking the "double sense of animated images" (Hernandez 1) and the 'inbetweening' process of animation. While Hernandez cites visual puns as an example of this dual language, humor is the excuse/justification of the dual/double sense created by animation. By humor as justification, I mean the doubleness, the exaggerated state, is done to create humor. The double sense of Boris is not a humorous one, instead it is a fearful one involving the grotesque display of the 'inbetweens.' Boris has multiple clones displayed throughout BATIM; however, these clones are incomplete and often are inactive/dead. The lack of voice for Boris places the focus entirely on his animated body. In other words, nothing distracts from his autonomy. For example, the first body the player sees in chapter one is the dissected and open body of a dead Boris; however, this body is not just displayed, it is shown as a site of commodification. Boris's diegetic body contains a tool Henry needs in order to fix the Ink Machine. The lack of humor regarding Boris is demonstrated during this objective. Since Boris's exposed and static body is the first corporeal body Henry/the player sees, the immediate objectification of the animated body 
juxtaposed to the poster version of Boris becomes the first sinister moment. The doubling occurs because Boris's body is a tool while still being a cartoon. It was from this doubleness the tone of mystery becomes sinister. Simultaneously, the doubleness of Boris comes from his diegetic replication within the game. Throughout the game, Henry encounters clones of Boris. Each Boris clone is slightly different; however, all are silent, voiceless. Boris is a double object: his existence is one of multiplicity because his character is cloned/repeatedly produced.

In addition to being a double object, Boris is also a liminal object. His clones are visualizations of the 'inbetween' process of animation, of industrialization. With each clone the internal machine (as represented by the wrench) becomes an externalized process. The first clone of Boris is dead with a wrench emerging from his stomach cavity while the next version of Boris Henry interacts with is alive. The third iteration of Boris, the only antagonistic Boris, has machines attached to his outer body and it is this version of Boris that attacks the player/Henry. The internal industrialization of his body becomes externalized and antagonistic. When Boris has the machines connected to his body, this is the only time Boris attacks the player/Henry. Liminality effects subjects though experience and liminality is a temporal and spatial dimension (Thomassen 2009). Boris is a liminal object because of the use of his body as a tool. The wrench Henry pulls from Boris's dead body forces Boris into a liminal state because he is 'inbetween' a body, a character and a tool. He is dead (rather there are clones of him who are dead) but he (this 
version of Boris) is also alive. The doubleness and liminal state of Boris is directly confronted and lingered over in the game.
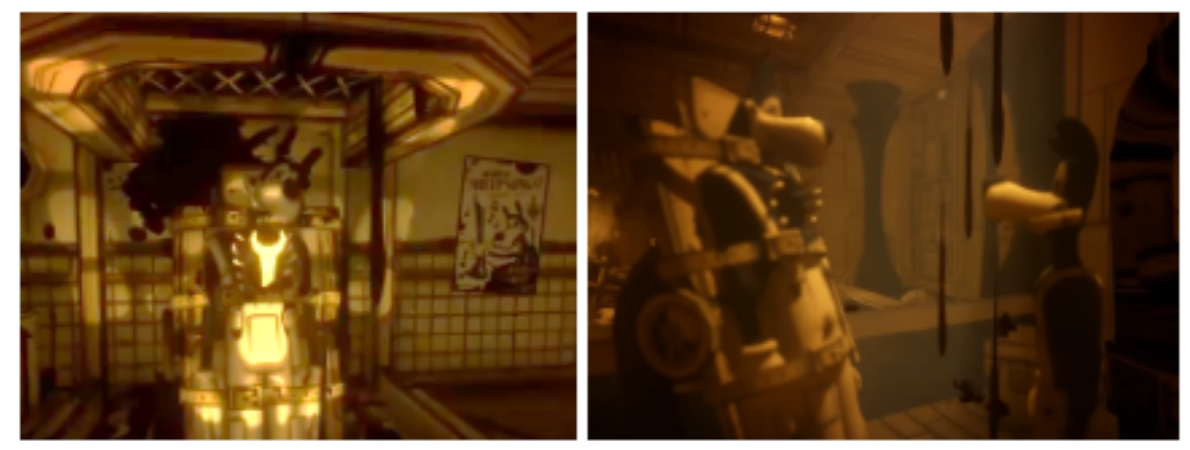

Figure 10: Dissected Boris

Unlike Bendy, Boris's corporeal bodies interact with each other through the gaze.

Boris is forced to confront his double existence. The silent confrontation of live Boris and dissected Boris represents a division of the True Self and the False Self (Winnicott 1960). This is where the gameic gaze comes in - the type of looking facilitated by the video game camera forcing the player to stare at the double bodies of Boris as Boris stares at his own clone. Boris, who never speaks, stares intensely at the dissected Boris, the same Boris the player/Henry retrieved a wrench from in the first chapter in order to fix the Ink Machine. As Boris looks at his dissected reflection, the player/Henry also stares.

Therefore, the gameic gaze is conducted by both the player and the characters within the diegetic and temporary world.

\section{Talkative Bodies}

While Boris represents the bending symptomatic of 'the inbetween process,' Alice Angel's multiple forms and multiple voices traces the compounded fracturing of the body by governmentality. Initially, the player/Henry is introduced to Alice Angel through recordings of Susie Campbell, the woman who voices Alice Angel. In these recordings, the distinction between Alice Angel and Susie Campbell is clear. However, when the corporeal form of Alice Angel is introduced, there are two voices speaking at 
once. The sonic doubleness of Alice becomes augmented by the appearance of Alice Angel's first corporeal form. This first form of Alice Angel has a split face, half is melted and half is intact.
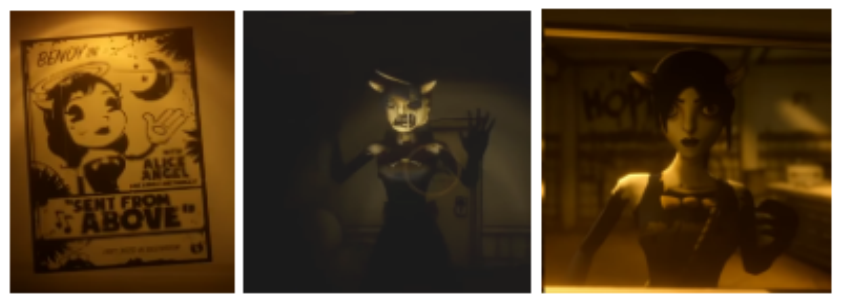

Figure 11: The multiple forms of Alice Angel

She constantly speaks of being an angel and the beauty required as well as her quest to remain beautiful. In her quest to maintain her angel status, Alice Angel regulates her body and the body of others including Boris and the dead. Alice Angel is the product and enforcer of governmentality. Her regulation of the bodies around her and her own body results in the demonization of Boris.

The antagonistic body, Sammy Lawrence, demonstrates how the regulation of looking of slaves enforced by minstrelsy becomes a fearful and violent form of selfgoverning. Like Alice Angel, there is a sonic duality of Sammy Lawrence. Sammy Lawrence speaks in Biblical riddles in the first audio log but in the second audio log Sammy Lawrence's speech is completely divorced from this religious diction. Sammy Lawrence refers to Bendy as "the figure of ink that shines in the darkness" recalling Bendy as his savior whom he prays to by singing "those old songs" (BATIM 2017). Music is explicitly linked to Sammy Lawrence's mode of worship through his verbal language. The use of Biblical language in the audio recordings is important for two reasons. Firstly, the Biblical language is an auditory representation of the fracturing of the replicated animated bodies. Secondly, the Biblical allusions facilitated by this type of language emphasizes the relationship displaces the tension between the Creator and His 
creations onto the Creator/Animator and created/animated. Sammy Lawrence is given a duality, an internal fracturing of the self which is reflected in his multiple recordings especially with the different tones in the first two recordings. Sammy Lawrence's duality is amplified through his Bendy mask. His mask allows Sammy Lawrence's True Self, his unseen self, to remain hidden by his projected self, his False Self. His Bendy masks acts as a veil, an external and internal separation. In The Souls of Black Folk. W.E.B. Du Bois identifies the division between white and Black Americans as a veil. Du Bois states that "I was different from other...shut out from their world by a vast veil" (Du Bois 8). From Du Bois's description, he posits the veil as an invisible barrier causing Black Americans to use a double-consciousness, a "sense of always looking at one's self through the eyes of others, of measuring one's soul by the tape of a world that looks on in amused contempt and pity" (Du Bois 9). Without using the psychoanalytic terms of Winnicott, Du Bois identifies a process of fracturing similar to the True and False Self; however, the division caused by the veil is one that becomes externalized by minstrelsy. The doubleconsciousness inflicting Black Americans, is a source of amusement, entertainment within minstrelsy. The blackface mask (and make up) is the physical form of Du Bois's veil because it is a symbol of the regulation of Black bodies as well as the separation of Black bodies from white bodies. Sammy Lawrence's Bendy mask is a veil in the Du Bois-ian sense because the mask allows Lawrence to hide his actual self and perform (Lawrence's perform is one of the violence) without questioning. The Bendy mask 
creates an external division just as the minstrel blackface, a mask of burnt cork, created division between Black bodies as Black identity and as entertainment objects.
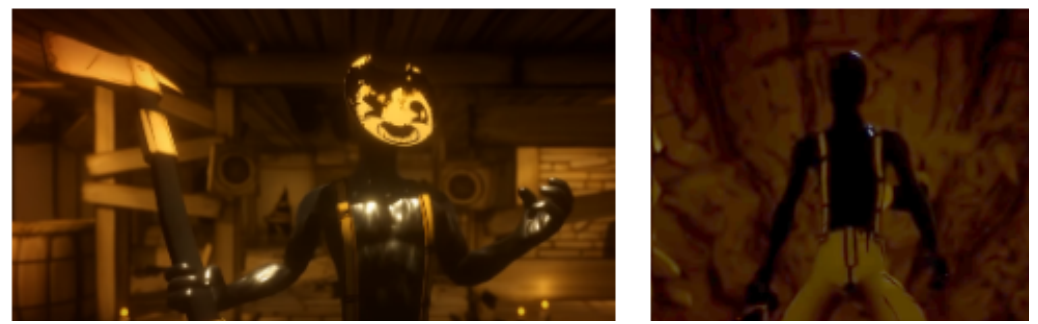

Figure 12: Sammy Lawrence with Bendy mask and without mask

During the player's/Henry's final encounter with Sammy Lawrence, the player/Henry removes the mask from Sammy Lawrence. Even though this removal is during an attack, Sammy Lawrence pauses his violent acts as he attempts to hide his face from the player/Henry. The power of the mask is revealed through this brief moment. Without his mask, Sammy Lawrence has lost his face, his means of communication; instead, the black ink covering his body is visible. The removal of the mask is an exposing and vulnerable experience for Sammy Lawrence, one resulting in the violent death of Sammy Lawrence. Without the mask, Sammy Lawrence has no power. The mask obscures the sight of the player. The maskless Sammy Lawrence means he can be looked at, stared at, examined. The removal of Sammy's mask is symbolic of the visibility the gametic gaze allows for: one staring at the bending of Black bodies.

\section{Disembodied Voices}

While Alice Angel and Sammy Lawrence are both characters with bodies and voices, there are also characters with voices but no bodies. A more complete hidden history of animation is also revealed auditorily through the disembodied voices of the employees of Joey Drew Studios. The voices of the Joey Drew Studios employees are accessible through an antiquated technology: the tape recorder. These recorders are placed throughout the game and provide a disjointed narrative about the happenings at 
the Studio. These audio logs incorporate the labor of animation history and the minstrel origins which became hidden through the creation of Steamboat Willie (Disney 1928) which is further compounded by the fact that the audio logs are hidden throughout the game. Additionally, most of these audio logs are not required for the narrative to progress. The hidden history of Joey Drew Studios is buried in these fragmented recordings and must be purposefully sought out much like the hidden history of American animation. The visibility and its relationship to animation history is directly engaged with by the tape recorders.

It is only through the convergence of the audio log and the diegetic moving ink that the history of the Studio is revealed. During the final chapter, an audio log labeled "Voice of UNKNOWN" is being played next to a puddle of bubbling ink. The screams playing on the audio log are muffled as if the subject of the scream was drowning in a thick liquid. Through this juxtaposition, it is suggested the employees of Joey Drew Studios were transformed into the ink monsters attacking and stalking Henry throughout the game. In fact, Joey Drew's own recording to Gent confirms this notion. In said recording, Drew states he owns plenty of souls to use in order to make living attractions. The employees are never shown; instead, the player/Henry only hears the echoes/ghosts of their voices before Drew sacrificed their souls to give life to his cartoons. It is this process, the removal of souls from body and transformation into an object, that is a sinister process. BATIM presents the commodification of both the animated bodies as well as the employees associated with labor. While Joey Drew views his capitalistic 
endeavors as a dreams, BATIM positions this type of capitalistic dream as a nightmare consuming biological and animated bodies.

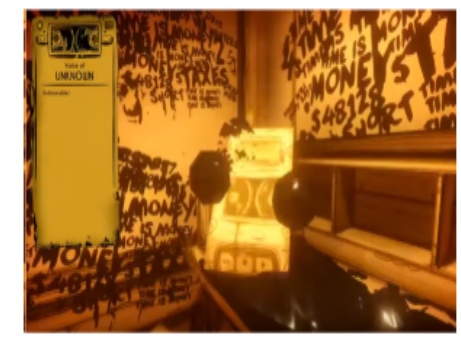

Figure 13: Unknown Audio Recording

Death and Dying by Ink

The bodies (both voiceless and talkative) and disembodied voices are bent until they die (disappear); therefore, the consequence of bending is death. The cycle of death is reminiscent of Sammond's claim that the 'cartoon character's disruption of the animated world of which it was a part marked the commodity's conventional and compulsive underlining (or delineation) and undermining of its own commodity status, the always failing fantasy of its autonomy" (Sammond 255). As a "death-denying" culture, the American animation industry also denies any pain associated with death and the finality of dying through the reversibility of the cartoon characters' deaths (Durkin 2003). BATIM saturates the animated space with images of and experiences of dying. Through act of repeated dying, the dream space of children's animation becomes a space of deadly nightmares. The process and act of dying is an essential part of play within video games. When an objective is failed, playable character dies; however, like in animation, death is not permanent. Dying is a cyclical process involving restarting and repeating. Like most video games, death in BATIM requires the repetition of the failed objective. The involvement of ink distinguishes the act of dying within BATIM from other games. The act of dying is a process inseparable from the diegetic ink. Since the playable character is Henry, the death of Henry is the most frequent death. All the characters, with the 
exception of two clones of Boris and one clone of Alice Angel, attack Henry with the intent to kill him. The characters, especially the ink monsters, originate from ink making ink the source of the threat of death. Ink is also the indicator of harm. When these characters attack Henry, the screen representing Henry's and the player's shared vision, becomes covered in ink much like other FPS games use the splattering of blood (red) to indicate the level of damage to the playable character. The more injuries Henry sustains, the more ink covers the screen suggesting Henry is bleeding ink. Yet, ink is also involved in the regeneration of Henry. Anytime Henry dies, Henry respawns from a tunnel of ink and emerges from the nearest Bendy statue. Henry is killed by bodies of ink, bleeds ink and is regenerated by ink; therefore, ink is the origin, the qualifier and the bringer of death. As demonstrated by Henry's repeated dying, ink is explicitly linked to a particularly repetitive cycle of production (life and death) within the animated space.
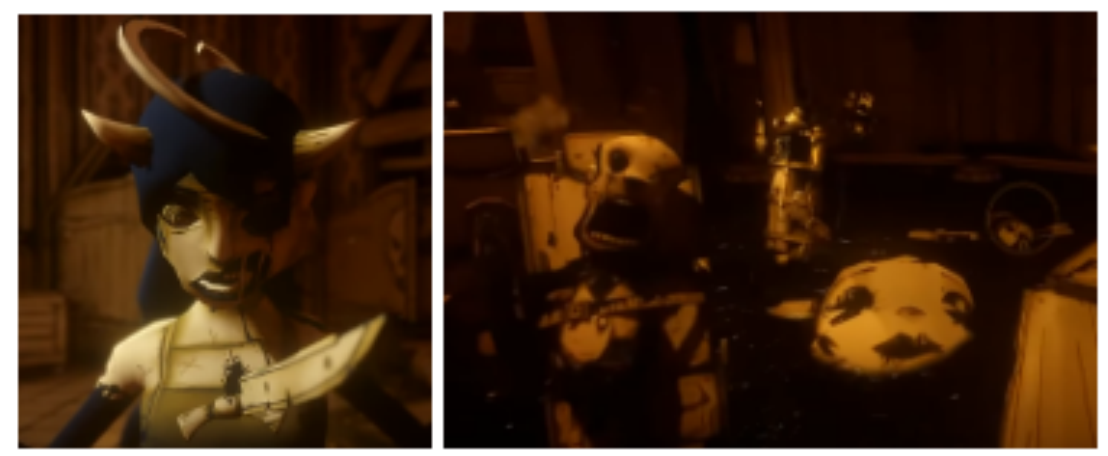

Figure 14: Death of cartoons

Death is not limited to Henry; rather, all the characters are explicitly connected to death. The act of dying and death are everywhere in BATIM precisely because ink is everywhere. All the primary antagonistic characters, Sammy Lawrence, Boris, Alice Angel, and Bendy die. Unlike the family friendly animation, death is a permanent state for the cartoons. Even though ink replaces blood, these death of the cartoons are still 
violent and gory. The disturbing execution of the cartoons opposes the family friendly belief of cartoons as a source of happiness - a sentiment echoed through Wally Franks in a recording where he states "these people gotta lighten up. I mean hello! You make cartoons! Your job is to make people laugh " (BATIM 2017). While each of these characters die in a different way, their deaths are unified through the inclusion of ink. Ink is always present. The repetitive nature of death is punctuated by the death of Bendy (Demon) and continued through the ending of the game's narrative.

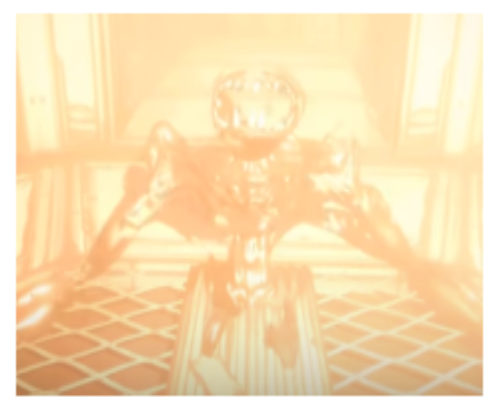

Figure 15: the Death of Bendy

Just as death and the act of dying within animation are cyclical processes, the game uses the final death and "escape" of Henry to solidify the inherent cyclicality of the animated space: a cyclicality dependent on the continued bending of the Black body. During the final chapter in the Ink Machine, Henry kills Bendy by playing the final film reel labeled "The End." After this moment, Henry is transported into a more realistic apartment where the player sees Joey Drew for the first time. Unlike the other characters in the game, Joey looks realistic. In the final scene, Henry steps through the door which seems to be the exit; however, Henry reappears in the first chapter in the same hallway the game started at. Henry is trapped in a cycle in which he must stay in the liminal space of the Studio. The diegetic world of BATIM is a cycle of hell where Henry must repeat the experience of fear in order to find hidden structures (writings) and learn more about the Studio's history. The cyclical nature of the game is important because it demonstrates 
the inescapability of the commodification of the Black body if not addressed directly and the frustration and fear created by this consumption.

\section{Conclusion}

Like Mickey Mouse, Bendy and all the cartoon character of BATIM are minstrels. Through bending, the act and displayed process within BATIM essential for seeing the images of minstrelsy, the mythos of animation as dreams is displaced by the largely unacknowledged origin/history of animation, Black bodies. Joey Drew Studios is not a place where dreams come true; rather, the studio is where nightmares come true. The hidden and subversive qualities of cartoons is placed at the forefront of the game through the fractured narration through tape recorders and the displaced ink. Joey Drew Studios' history and decay is never directly stated, instead, the player/Henry must piece together the narration through non-chronological fragments while other parts of the history are inaccessible because of ink. The bodily contortion of the Black body into an entertainment object, the minstrel/cartoon, also becomes accessible through fear. Instead of looking to the cartoon as a source of playfulness and laughter, the player is condition to fear the bodies of the cartoons because of their destructive power. The minstrel cartoons become minstrel monsters with the space of the game. As demonstrated through the play of BATIM, minstrelsy is not a performance of the past; rather, minstrelsy is a contemporary performance hidden within American popular culture particularly cartoons. BATIM legitimizes the problematic history of animation not through the justification of the use of Black bodies as entertainment objects but by making the bending of the Black body by the animation industry visible through the gameic gaze. 
Thesis Bibliography

Ahmed, Sara. "Happy Objects." The Affect Theory Reader, Durham: Duke University Press, 2010.

Bantinaki, Katerina. "The Paradox of Horror: Fear as a Positive Emotion" The Journal of Aesthetics and Art Criticism. Vol. 70, No. 4, (Fall 2012) pp. 383 - 392.

Black, Gregory. "Hollywood Censored: The Production Code Administration and the Hollywood Film Industry, 1930 - 1940," Film History, Vol. 3, No. 3 (1989), pp.167-189.

Bloomsquist, Jennifer. "The Minstrel Legacy: African American English and the Construction of 'Black' Identities in Entertainment." Journal of African American Studies, no. 4 (Dec 2015): pp. 410-426.

Bollas, Christopher. "The Transmissive Self and Transmissive Objects in the Age of Globalization." Studies in Comparative Literature 2015, Vol 81,p.15-33.

Bordo, Susan. Unbearable Weight: Feminism, Western Culture and the Body. Berkeley: University of California Press, 1993.

Brooker, Will. 'Camera-Eye, CG-Eye: Videogames and the 'Cinematic,' Cinema Journal, Vol. 48, No. 3 (Spring, 2009), pp. 122 - 128.

Brown, Noel. The Hollywood Family Film: A History, from Shirley Temple to Harry Potter. New York: I.B. Tauris \& Co Ltd, 2012.

Campbell, Nancy. Collection 102. Swanee River PCA Files, Special Collection, Motion Picture Association of America. Production Code Administration records. Margaret Herrick Library, Beverly Hills. 23 April 2018.

Clifton, James, "The Face of a Fiend: Convulsion, Inversion \& the Horror of Disempowered Body" Oxford Art Journal, Vol. 34, No. , Early Modern Horror (2011), pp.373 - 392 .

Cole, Catherine and Tracy Davis. "Routes of Blackface," TDR, Vol. 57, No. 2, (Summer 2013), pp. 7 -12.

Crawford, Richard. "Blacks, Whites and the Minstrel Stage," In A History: America's Musical Life. New York: W.W. Norton \& Company, 2001. 
Depoorter, Ben. "The Several Lives of Mickey Mouse: The Expanding Boundaries of Intellectual Property Law," Virginia Journal of Law \& Technology 4 (2004).

Du Bois, W. E. B. The Souls of Black Folk. The Pennsylvania State University, 2006. eBook.

Dunson, Stephanie. "The Minstrel in the Parlor: Nineteenth-Century Sheet Music and the Domestication of Blackface Minstrelsy." ATQ (The American Transcendental Quarterly), no. 4 (Dec 2002): pp.241-256.

Durkin, Keith "Death, Dying, and the Dead in Popular Culture." Handbook of Death \& Dying, edited by Clifton Bryant, SAGE publications, 2003, pp. 43 49.

Foucault, Michel. The Foucault Reader, edited by Paul Rabinow, Pantheon Books, 1984.

Foucault, Michel. Power edited by James Faubion, The New Press, 2000.

Galloway, Alexander. "Gamic Action, Four Moments.” Gaming: Essays on Algorithmic Culture. Minneapolis: University of Minnesota Press. 2006.

Hernandez, Maria. "The Double Sense of Animated Images. A View on the Paradoxes of Animation as a Visual Language," Animation Studies Online Journal, (2008).

Hobbs, Priscilla. Walt's Utopia: Disneyland and American Mythmaking. North Carolina: McFarland \& company, Inc., Publishers, 2015.

Hochschild, Jennifer. Facing Up to the American Dream: Race, Class, and the Soul of the Nation. Princeton: Princeton University Press, 1995.

hooks, bell. Reel to Real: Race, sex, and class at the movies. New York: Routledge, 1996.

Huizinga, J. Homo Ludens. Routledge, 2014. pp. 1- 27.

Kootin, Amma. "Lessons in Blackbody Minstrelsy: Old Plantation and the Manufacture of Black Authenticity" TDR, Vol 57, No 2 (Summer 2013), pp. 102 - 122.

Jameson, Fredric. "Benjamin Walter, or Nostalgia” Salmagundi, No. 10/11 (Fall 1969 Winter 1970), pp. 52-68.

Jansz, Jeroen. "Playing out identities and emotions." Playful Identities ed. Valeri Frissen, Sybille Lammes, Michiel de Langue, Jos de Mul, Joost Raessens. Amsterdam University Press (2015). 
Jenkins, Henry. “Game Design as Narrative Architecture.” First Person: New Media as Story, Performance and Game edited by Noah Wardrip-Fruin and Pat Harrigan, The MIT Press, 2004, pp. 118 - 130.

Jones, Douglas. "Black Politics not Black People: Rethinking the Social and 'Racial' History of Early Minstrelsy." The Drama Review, no. 2 (Summer 2013): pp. 21 37.

Knight, Arthur. “'Fool Acts': Cinematic Conjunctions of White Blackface and Black Performance" in Disintegrating the Musical: Black Performance and American Musical Film. Durham: Duke University Press, 2002.

Lakwete, Angela. Inventing the Cotton Gin: Machine and Myth in Antebellum America. Baltimore: John Hopkins University Press, 2003.

Lehman, Christopher "The Colored Cartoon: Black Presentation in American Animated Short Films, 1907 - 1954.” eBook.

Lhamon, W.T.. Blackface Performance from Jim Crow to Hip Hop. Cambridge: Harvard University Press, 1998.

Lott, Eric. Love and Theft: Blackface Minstrelsy and the American Working Class. New York: Oxford University Press, 1993.

Mahar, William. Behind the Burnt Cork Mask: Early Blackface Minstrelsy and Antebellum American Popular Culture. Chicago: University of Illinois Press, 1999.

Mendelssohn, Michele. "Rewriting the Genealogy of Minstrelsy for Modernity: 'Cry and Sing, Walk and Rage, Scream and Dance',' African American Review, Vol. 48, No. 1/2 (Spring/Summer 2015), pp.127-139.

Pallant, Chris. Demystifying Disney: A History of Disney Feature Animation. London: Bloomsbury, 2011.

Pallant, Chris. "Video Games and Animation." The Animation Studies Reader, edited by Nichola Dobson, Annabelle Roe, Amy Ratelle, Caroline Ruddell, Bloomsbury Publishing, 2018, pp. 305-324.

Petty, Miriam. "Lincoln Perry's 'Problematic Stardom': Stepin Fetchit Steals the Shoat." In Stealing the Show: African American Performers and Audiences in the 1930s Hollywood. Oakland: University of California Press, 2016.

Post, Tina. "Williams, Walker, and Shine: Blackbody Blackface, or the Importance of Being Surface." The Drama Review, no. 4 (Winter 2015): pp. 83- 100. 
Power, Pat. "Ludic Toons: The Dynamics of Creative Play in Studio Animation" American Journal of Play, no. 1 (2012).

Power, Pat. "Playing with Ideas: The Affective Dynamics of Creative Play," American Journal Play, no. 3 (2011).

Powell, Anna. Deleuze And Horror Film. Edinburgh: Edinburgh University Press, 2005.

Ratelle, Amy. “Animation and/as Children's Entertainment” The Animation Studies Reader, edited by Nichola Dobson, Annabelle Roe, Amy Ratelle, Caroline Ruddell, Bloomsbury Publishing, 2018, pp. 286 - 304.

Sammond, Nicholas. Birth of an Industry: Blackface Minstrelsy and the Rise of American Animation. Duke University Press, 2015.

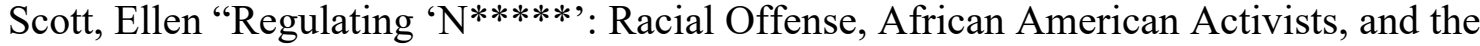
MPPDA, 1928-1961,” Film History, Vol 26, (2014), pp. 1 - 31.

Spadoni, Robert. Uncanny Bodies: The Coming of Sound Film \& the Origins of the Horror Genre. Berkeley: University of California Press. 2007. eBook.

Smuts, Aaron. "What is Interactivity?" The Journal of Aesthetic Education, Vol. 43, No. 4 (Winter 2009), pp. 53-73. University of Illinois Press.

Sutton-Smith, Brian. "Play and Ambiguity" in The Ambiguity of Play. Cambridge: Harvard University Press, 2001.

Telotte, J.P. "Sound Fantasy" in The Mouse Machine: Disney and Technology. Chicago: University of Illinois Press, 2008.

Telotte, J.P. “The Stereoscopic Mickey: Space, Animation, and the Mouse” Journal of Popular Film and Television, 2008.

Therrien, Carl. "Games of Fear: A Multi-Faceted Historical Account of the Horror Genre in Video Games." In Horror Video Games: Essays on the Fusion of Fear and Play, edited by Bernard Perron, Jefferson, N.C.: McFarland \& Co, 2009.

Thomassen, Bjorn. "The Uses and Meaning of Liminality" International Political Anthropology Vol. 2, No. 1, (2009), pp. 6-27.

Vaughn, Stephen. "Morality and Entertainment: The Origins of the Motion Picture Production Code," The Journal of American History, Vol. 77. No. 1 (June, 1990), pp. $39-65$. 
Walden, Victoria. "Animation and Memory." The Animation Studies Reader, edited by Nichola Dobson, Annabelle Roe, Amy Ratelle, Caroline Ruddell, Bloomsbury Publishing, 2018, pp.133 - 149.

Whitley, David. "Learning with Disney: Children's Animation and the Politics of Innocence," Journal of Educational Media, Memory \& Society, Vol. 5, No. 2 (Autumn 2013), pp. 75 - 91.

Williams, Linda. "Film Bodies: Gender, Genre, and Excess," Film Quarterly, Vol.44, No. 4 (Summer, 1991), pp.2-13.

Winas, Robert and Elias Kaufman. "Minstrel and Classic Banjo: American and English Connections," American Music, Vol. 12, No. 1 (Spring, 1994), pp.1 - 30.

Winnicott, D. W. "Transitional Objects and Transitional Phenomena" in Playing \& Reality. London: Tavistock Publications, 1971.

Winnicott, D.W. The Maturational Processes and the Facilitating Environment: Studies in the Theory of Emotional Development. New York: International Universities Press, Inc, 1960. 